\title{
Tecnologia Supercrítica: Passado, Presente, Futuro
}

$\mathrm{E}$ EM 1988 fol Publicado No Boletim de Biotecnologia um artigo [1] com o título "Extracção Supercrítica: Mito ou Realidade?". Estávamos então no início do desenvolvimento da investigação com fluidos supercríticos, iniciada no nosso País pelo Manuel Nunes da Ponte (Departamento de Química, FCT, Universidade Nova de Lisboa, Monte de Caparica) e por mim em 1985 no Centro de Química Estrutural (I.S.T.).

Após o entusiasmo geral que se verificou na década de ' 80 , e à sua consolidação como ciência aplicada nos anos '90, assistimos presentemente a um desenvolvimento alucinante da tecnologia supercrítica. Estes factos são facilmente comprováveis pelo enorme aumento do número total de patentes registadas anualmente envolvendo a utilização de fluidos supercríticos (FSC), conforme mostra a figura 1. Do mesmo modo, as poucas (menos de 10) grandes instalações industriais usando FSC existentes na década de 80 passaram para mais de 50 em finais de 2000 .

\section{A década de ' 80}

Em meados da década de oitenta a tecnologia supercrítica ainda estava na sua infância. Ensaiava os primeiros passos nas aplicações industriais (por exemplo, na extracção da cafeína dos grãos de café) e esta tecnologia era olhada como "temos solução para os problemas ... mas não temos os problemas" como me disse na altura um ilustríssimo termodi- nâmico americano. De facto era assim. $E$ isto reflecte-se bem se olharmos para as publicações da década de '80: a maioria envolve a aplicação dos fluidos supercríticos em problemas de extracção de produtos naturais e biológicos. Azeite, óleo de eucalipto (limoneno, cineol, pinenos), aromas [2], aditivos alimentares, extractos de plantas (gerânio), tocoferol, glicidol, vinho [3], madeira de eucalipto foram alguns dos produtos relevantes para a economia do nosso País ou de interesse tecnológico aos quais aplicámos a tecnologia supercrítica. Sem surpresa (atendendo às vantagens inerentes à aplicação dos FSC), verificamos assim que na década de ' 80 a investigação com FSC foi aplicada principalmente (e também no es-

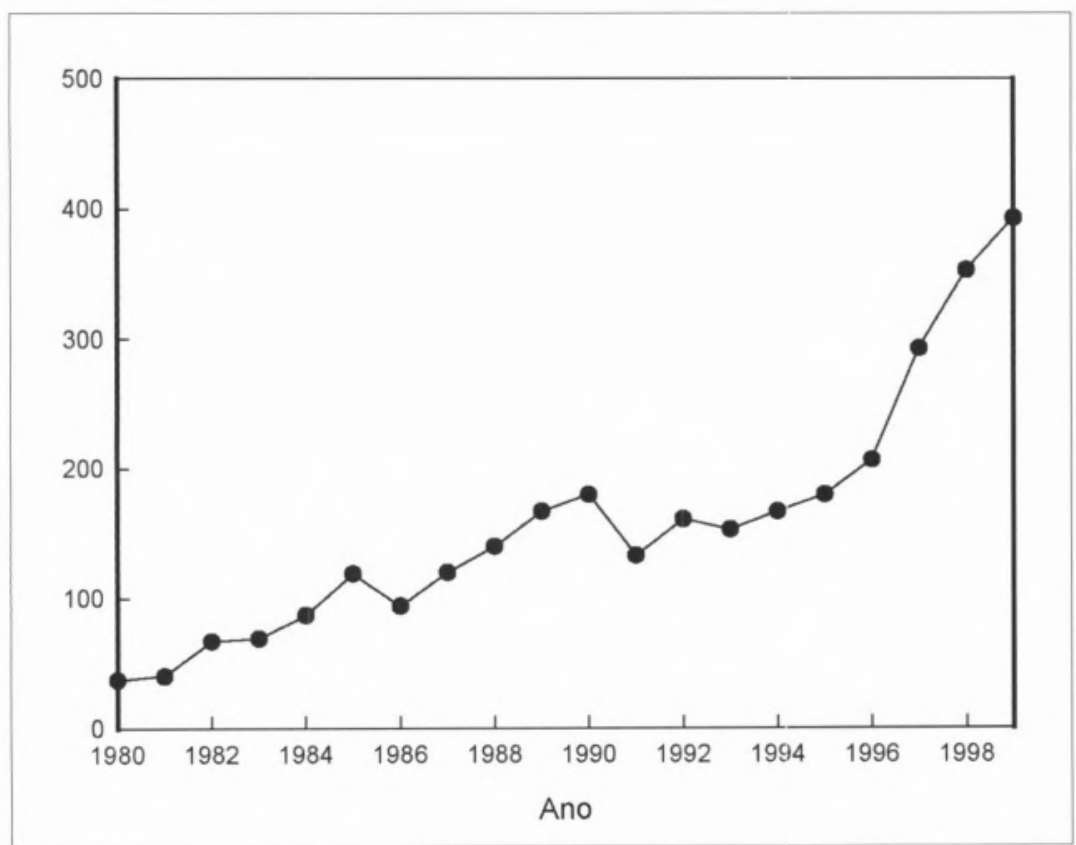

figura 1 Tecnologia supercrítica: Número de patentes registadas por ano.

\footnotetext{
*Centro Química Estrutural, Departamento de Engenharia Química, Instituto Superior Técnico, Av. Rovisco Pais, 1049-001 Lisboa, e-mail: egazevedo@ist.utl.pt
} 


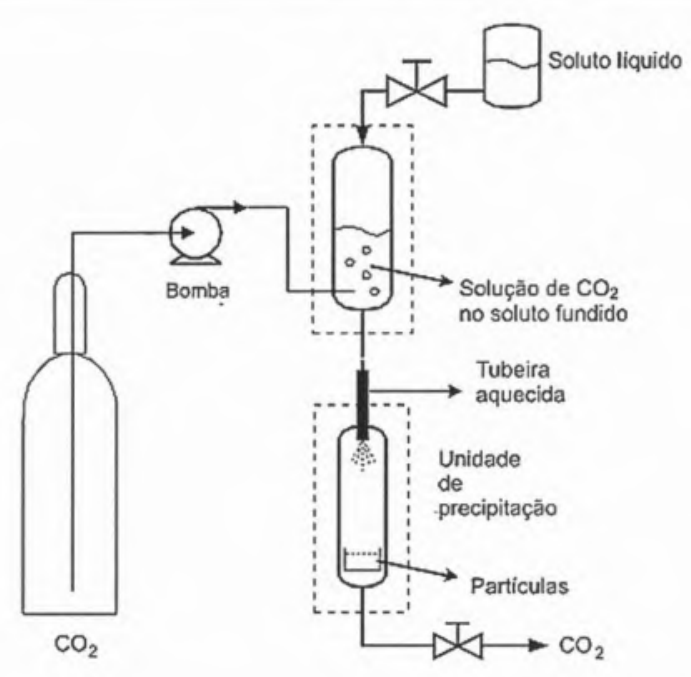

trangeiro) a problemas de extracção de produtos naturais ou de origem biológica. Estas aplicações exigiram na maior parte dos casos dados termodinâmicos de sistemas (binários e ternários) com os elementos constituintes dos produtos naturais e o $\mathrm{FSC}\left(\mathrm{CO}_{2}\right.$, etano, eteno, etc.). Por isso, foram também publicados nesta década (e seguintes) muitos trabalhos com a determinação experimental e modelação de dados de equilibrio líquido-vapor [4] e de propriedades de transporte [5], como suporte para o projecto de instalações de extracção à escala piloto ou mesmo industrial.

\section{A década de '90}

Os anos noventa trouxeram grandes avanços da tecnologia supercrítica aplicada à síntese química, incluindo as reacções catalíticas, e às reacções de oxidação com água supercrítica, onde os FSC serviam de meio reaccional e podiam também substituir vantajosamente os solventes tradicionais. De particular interesse foi a integração da reacção com um processo de separação, onde o FSC servia tanto como meio reaccional como de reagente como, por exemplo, na reacção de formação do ácido fórmiCo a partir da hidrogenação do $\mathrm{CO}_{2}$. $\mathrm{O}$ $\mathrm{CO}_{2}$ supercrítico é um solvente particularmente adequado para ser usado na síntese orgânica (em reacções homogéneas e em reacções catalíticas) e no processamento de material orgânico, pois as suas propriedades de solvente (por exemplo, o parâmetro de solubilidade $\delta$ ) é semelhante ao de um líquido orgânico não polar como o hexano. Pode por isso dissolver compostos não polares ou pouco polares de massa molar baixa. Muitas vezes, perto da zona crítica observa-se um aumento significativo da sua selectividade reaccional. Metanol supercrítico (cujas constantes críticas são intermédias entre as do $\mathrm{CO}_{2}$ e as da água) foi usado na reciclagem de alguns polímeros de condensação como o teraftalato de polietileno. De realçar o enorme desenvolvimento nesta década das aplicações com água supercrítica (apesar do seu ponto critico muito elevado, $674.3 \mathrm{~K}$ e $22.12 \mathrm{MPa}$ ) em reacções de oxidação, nomeadamente na destruição (rápida) de efluentes e de material muito tóxico, onde se incluem as armas químicas. $\mathrm{A}$ água supercrítica apresenta condições particularmente adequadas pois, por exemplo, a sua constante dieléctrica passa de 78.5 em condições de pressão e de temperatura normais para cerca de 6 a $675 \mathrm{~K} \mathrm{e} 30 \mathrm{MPa}$. A alteração significativa desta (e de outras) propriedade física da água origina que em condições supercríticas a água seja um bom solvente de muitos compostos orgânicos incluindo compostos aromáticos clorados como os PCBs, dioxinas e furanos pois não ocorrem reacções iónicas e o meio reaccional favorece as reacções radicalares. Porém, a utilização da acção oxi- figura 2 Esquema de uma instalação PGSS para produção de micropartículas usando $\mathrm{CO}_{2}$ supercrítico.

dativa da água supercrítica é ainda sob o ponto de vista industrial um problema complicado devido à corrosão nas paredes dos reactores (mesmo que sejam em aço inoxidável!) pois a água supercrítica não dissolve totalmente os sais inorgânicos (por exemplo, no tratamento de compostos halogenados, os iões halogéneo tendem a formar os respectivos ácidos que são altamente corrosivos). 0 primeiro reactor usando água supercrítica foi instalado em 1995 em Austin, (Texas, E.U.A.). Tinha capacidade para tratar $25 \mathrm{~L} / \mathrm{min}$ de um efluente aquoso contendo $10 \%$ de compostos orgânicos, com um grau de purificação do efluente que excedia os $99.5 \%$. No Japão foi instalada em 1998 a primeira unidade comercial de reciclagem envolvendo hidrólise com água supercrítica.

Não é pois de admirar que a década de 90 tenha sido a década das reacções e que tenhamos assistido ao desenvolvimento de um grande número de aplicações dos fluidos supercríticos como solventes em reacções de síntese orgânica, processamento de polímeros, reacções enzimáticas, etc., incluindo algumas aplicações a nível industrial.

\section{O presente}

Ao último encontro que reúne regularmente os especialistas desta área (6th International Symposium on Supercritical Fluids) realizado em Versalhes, 
figura 3 Fotografia obtida por espectroscopia electrónica de varrimento e distribuição de tamanhos de partículas de teofilina encapsuladas em óleo de palma hidrogenado produzidas por PGSS. Diâmetro da tubeira: 25 $\mu \mathrm{m}$; temperatura de pré-expansão: $86^{\circ} \mathrm{C}$ pressão de pré-expansão: $18 \mathrm{MPa}$.

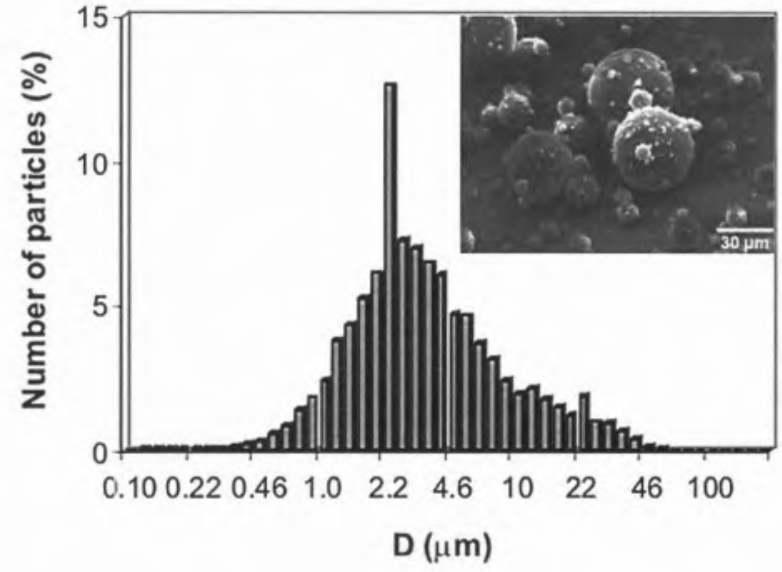

bressaturação, conduzindo à precipitação do soluto sob a forma de partículas muito finas e pequenas e com uma reduzida distribuição de tamanhos. Alterando as variáveis do processo, nomeadamente a temperatura e pressão da expansão, diâmetro da tubeira, etc., é possível controlar o diâmetro médio das partículas e a sua distribuição de tamanhos. Contudo, em muitos casos, a tecnologia SAS (Supercritical Anti-Solvent) é mais adequada pois não requer que o soluto seja solúvel no FSC como é exigido pela técnica RESS. No processo SAS, as partículas são formadas por dissolução do FSC numa solução saturada do soluto. A dissolução do FSC na solução provoca uma grande expansão do volume da solução, actuando como um antisolvente, o que provoca a formação de cristais do soluto.

A figura 2 apresenta esquematicamente uma instalação de formação de partículas de medicamentos encapsulados usando FSC através da tecnologia PGSS (Particles from Gas Saturared Solutions).

Num misturador, o encapsulante e o soluto são solubilizados com o FSC. A mistura ternária resultante é expandida através de uma tubeira aquecida até à pressão atmosférica. Esta expansão origina partículas de tamanhos e formas variáveis. Foi deste modo que foram obtidas [6] as micropartículas de teofilina (um broncodilatador usado no trata- mento da asma) encapsuladas em óleo de palma hidrogenado, apresentadas na figura 3.

Conforma mostra a figura 3 , as partículas de teofilina têm uma forma esférica com diâmetro médio relativamente pequeno. A distribuição de tamanhos da figura 3 indica que nas condições experimentais apresentadas a maior parte das partículas têm um diâmetro inferior a $5 \mu \mathrm{m}$, como aliás é exigido na administração deste medicamento por inalação. Os resultados da distribuição de tamanhos são obtidos usando um analisador de partículas que mede o tempo de voo das partículas aceleradas por ar supersónico, fazendo-se normalmente um mínimo de 20.000 mediçōes por amostra. Estes ensaios de formação de partículas com $\mathrm{CO}_{2}$ supercrítico são efectuados sob várias condições experimentais, nomeadamente a diferentes pressões de expansão e temperaturas de pré-expansão, com o objectivo de estudar como estes parâmetros de processo influenciam a morfologia das partículas e a sua distribuição de tamanhos.

\section{O futuro}

Após termos assistido a um crescimento constante desta tecnologia durante os últimos 20 anos, é de esperar que num futuro próximo se iniciem os grandes investimentos em instalaçōes ligadas à produção e também ao desenvolvimen- dezenas de microns). Esta descompressão provoca um aumento rápido da so- 
to de outras aplicações inovadoras. De facto, foram realizados recentemente nos EUA investimentos significativos em áreas como a produção de polímeros e de revestimentos e no Reino Unido em aplicações de síntese química. Também estão em desenvolvimento unidades destinadas à remoção de pesticidas e até máquinas de limpeza a seco onde o fluido de lavagem é o $\mathrm{CO}_{2}$ ! No norte da Europa está em testes finais de funcionamento uma unidade de conservação de madeira baseada na impregnação com $\mathrm{CO}_{2}$ supercrítico. No Japão, processos envolvendo oxidação com água supercrítica funcionam já à escala industrial, sendo de esperar grandes investimentos em novas aplicações nomeadamente nas indústrias química, farmacêutica, do papel, de tratamento de efluentes, síntese de nanopartículas, reacções de polimerização, etc.
Extracção supercrítica: mito ou realidade? O leitor que decida!

\section{Dedicatória}

Ao Jorge Calado, inesgotável inspirador da procura do saber, do rigor e da verdade.

\section{Bibliografia}

[1] J. C. Revés, M. Nunes da Ponte, E. Gomes de Azevedo, "Extracção Supercrítica: Mito ou Realidade?", Bol. de Biotecnologia, 1988, 36: 11.

[2] H. A. Matos, P. C. Simões, E. Gomes de Azevedo, M. T. Carrondo, M. Nunes da Ponte, "Phase Equilibria of Natural Flavors and Supercritical Solvents", Fluid Phase Equilibria, 1989, 52: 357-364.
[3] M. Nunes da Ponte, J. Revés, A. R. Machado, S. Fernandes, J. Lopes, E. Gomes de Azevedo, "Processo de Extracção de Aromas de Mostos de Vinho Utilizando Fluidos Supercríticos*, 1999, Patente de Invenção N. ${ }^{\circ}$ 101590.

[4] M. A. Costa, H. A. Matos, M. Nunes da Ponte, E. Gomes de Azevedo, "Binary and Ternary Phase Behavior of $\alpha$-Pinene, $\beta$-Pinene and Supercritical Ethene", J. Chem. Eng. Data, 1996, 41: 1104-1110.

[5] P. C. Simões, H. A. Matos, P. J. Carmelo, E. Gomes de Azevedo, M. Nunes da Ponte 'Mass Transfer in Countercurrent Packed Columns - Application to Supercritical $\mathrm{CO}_{2}$ Extraction of Terpenes", Ind. Eng. Chem. Res., 1995, 34: 613-618.

[6] M. Rodrigues, N. Peiriço, H. A. Matos, E. Gomes de Azevedo, M. R. Lobato, A. Almeida, "Microcomposites Theophylline/Hydrogenated Palm Oil from a PGSS Process for Controlled Drug Delivery Systems", J. Supercritical Fluids, 2003, em impressão.
$\mathrm{F}$ II CONVIDADO PARA ESCREVER UM ARTIGO sobre o Jorge Calado. Disse que o faria com prazer e sem esforço, no período da Páscoa.

Infelizmente, para mim, fui confrontado com uma grave catástrofe familiar que me impede de ter ideias, neste momento: os meus Pais morreram num desastre inaceitável.

O que iria dizer em condições normais?

Iria focar a indisfarçável influência que ele teve nas (nossas) minhas opções profissionais. Iria focar, também, o papel que ele teve na opção científica que tomei quando era um simples Assistente Eventual. Não esqueceria, nem nunca esquecerei, a influência que teve na minha formação humana e cultural (o meu gosto pela ópera e pela música clássica a ele se deve). Não deixaria de focar o seu papel fundamental na obtenção do meu doutoramento, como iria referir a sua influência determinante na criação de uma Escola de Termodinâmica Química que hoje se espalhou e é um exemplo a nível nacional (e, até, internacional).
Iria igualmente referir a sua influência no meu comportamento. A sua honestidade intelectual está acima de todas as suspeitas e transmite aos seus colaboradores uma confiança não habitual em Portugal. Aprendi com ele a ser intelectualmente honesto e a conviver com aqueles que o não são.

Gostaria de ser mais claro e mais positivo. Não consigo. Os meus Pais morreram em situação indescritivel e falta-me a palavra para ser mais claro.

\footnotetext{
*Departamento de Química e Bioquímica, Faculdade de Ciências da Universidade de Lisboa
} 